University of South Carolina

Scholar Commons

$7-2011$

\title{
Serum IGF-1 Concentrations Change With Soy and Seaweed Supplements in Healthy Postmenopausal American Women
}

\author{
Jane Teas \\ University of South Carolina - Columbia \\ Mohammad R. Irhimeh \\ Susan Druker \\ Thomas G. Hurley \\ University of South Carolina - Columbia \\ James R. Hébert \\ University of South Carolina - Columbia, jhebert@sc.edu \\ See next page for additional authors \\ Follow this and additional works at: https://scholarcommons.sc.edu/ \\ sph_epidemiology_biostatistics_facpub \\ Part of the Public Health Commons
}

\author{
Publication Info \\ Postprint version. Published in Nutrition and Cancer, Volume 63, Issue 5, 2011, pages 743-748. \\ This is an electronic version of an article published in: \\ Teas, J., Irhimeh, M.R., Druker, S., Hurley, T.G., Hébert, J.R., Savarese, T.M., \& Kurzer, M.S. (2011). Serum \\ IGF-1 Concentrations Change With Soy and Seaweed Supplements in Healthy Postmenopausal American \\ Women. Nutrition and Cancer, 63(5), 743-748. DOI: 10.1080/01635581.2011.579383 \\ Nutrition and Cancer is available online at: www.tandfonline.com. \\ (c) 2011 Taylor \& Francis.
}

This Article is brought to you by the Epidemiology and Biostatistics at Scholar Commons. It has been accepted for inclusion in Faculty Publications by an authorized administrator of Scholar Commons. For more information, please contact digres@mailbox.sc.edu. 


\section{Author(s)}

Jane Teas, Mohammad R. Irhimeh, Susan Druker, Thomas G. Hurley, James R. Hébert, Todd M. Savarese, and Mindy S. Kurzer 


\title{
Serum IGF-1 Concentrations Change With Soy and Seaweed Supplements in Healthy Postmenopausal American Women
}

\author{
Jane Teas, \\ Cancer Research Center of the University of South Carolina, Columbia, South Carolina, USA \\ Mohammad R. Irhimeh, \\ Save Sight Institute, Sydney Hospital, University of Sydney, Sydney, Australia

\section{Susan Druker,} \\ Department of Preventive Behavioral Medicine, University of Massachusetts Medical School, \\ Worcester, Massachusetts, USA

\section{Thomas G. Hurley,} \\ Cancer Research Center of the University of South Carolina, Columbia, South Carolina, USA; \\ South Carolina Statewide Cancer Prevention and Control Program, Columbia, South Carolina, \\ USA; and Department of Biostatistics and Epidemiology, Arnold School of Public Health, \\ University of South Carolina, Columbia, South Carolina, USA
}

\section{James R. Hébert, Cancer Research Center of the University of South Carolina, Columbia, South Carolina, USA; South Carolina Statewide Cancer Prevention and Control Program, Columbia, South Carolina, USA; and Department of Biostatistics and Epidemiology, Arnold School of Public Health, University of South Carolina, Columbia, South Carolina, USA}

Todd M. Savarese, and Department of Cancer Biology and Cancer Center, University of Massachusetts Medical School, Worcester, Massachusetts, USA

\section{Mindy S. Kurzer \\ Department of Food Science and Nutrition, University of Minnesota, St. Paul, Minnesota, USA}

\section{Abstract}

\begin{abstract}
Insulin-like growth factor 1 (IGF-1) is an anabolic hormone important for growth and development. However, high-circulating serum concentrations in adults are associated with increased risk of postmenopausal breast cancer. Nutritional status and specific foods influence serum IGF-1 concentrations. Breast cancer incidence is typically low in Asian countries where soy is commonly consumed. Paradoxically, soy supplement trials in American women have reported significant increases in IGF-1. Seaweed also is consumed regularly in Asian countries where breast cancer risk is low. We investigated the possibility that seaweed could modify soy-associated increases in IGF-1 in American women. Thirty healthy postmenopausal women (mean age $58 \mathrm{yr}$ ) participated in this 14-wk double-blinded, randomized, placebo-controlled crossover clinical trial.
\end{abstract}

\footnotetext{
Copyright $\odot$ Taylor \& Francis Group, LLC

Address correspondence to Jane Teas, PhD, Cancer Research Center, University of South Carolina, 915 Greene Street, Suite 200, Columbia, SC 29208, USA. Phone: +1 803315 5851. Fax: +1 803576 5624., teas@ mailbox.sc.edu.

JT and MSK designed the research; JT, SD, and TS conducted research; TGH and JRH analyzed the data; JT and MI wrote the paper; JT had the primary responsibility for the final content. All authors read and approved the final manuscript.

Jane Teas, Mohammad Irhimeh, Susan Druker, Thomas Hurley, James Hébert, and Todd Savarese have no conflicts of interest; Mindy Kurzer is a member of the Soy Nutrition Institute Scientific Advisory Board.
} 
Participants consumed $5 \mathrm{~g} /$ day placebo or seaweed (Alaria esculenta) in capsules for $7 \mathrm{wk}$. During the 7th wk, a high-soy protein isolate powder was added $(2 \mathrm{mg} / \mathrm{kg}$ body weight aglycone equivalent isoflavones). Overnight fasting blood samples were collected after each intervention period. Soy significantly increased serum IGF-1 concentrations compared to the placebo (21.2 $\mathrm{nmol} / \mathrm{L}$ for soy vs. $16.9 \mathrm{nmol} / \mathrm{L}$ for placebo; $P=0.0001)$. The combination of seaweed and soy significantly reduced this increase by about $40 \%(21.2 \mathrm{nmol} / \mathrm{L}$ for soy alone vs. $19.4 \mathrm{nmol} / \mathrm{L} ; P=$ 0.01 ). Concurrent seaweed and soy consumption may be important in modifying the effect of soy on IGF-1 serum concentrations.

\section{INTRODUCTION}

Breast cancer rates are remarkably different even among developed countries. Japanese women living in Japan have about one quarter the rate of breast cancer as that of women in other industrialized nations (1), and the differences are particularly evident after menopause, when breast cancer rates continue to rise with age elsewhere but plateau in Japan. The rate of breast cancer almost doubles in the first 10 years after Japanese women immigrate to the United States, and this difference is thought to be related to environmental and lifestyle factors, especially diet $(2,3)$.

An important biomarker of breast cancer risk is serum insulin-like growth factor (IGF-1). A meta-analysis of 17 studies of breast cancer and serum IGF-1 concentrations reported that high serum concentrations of IGF-1 were associated with increased postmenopausal breast cancer risk (4). Laboratory data support a role for the IGF-1 signaling pathway in carcinogenesis, with increased DNA synthesis and decreased cell cycle regulation leading to inhibition of apoptosis (5). Blocking this pathway has been shown to benefit cancer patients (6).

Serum IGF-1 concentrations can be modified by diet, including dairy products and tomatoderived foods $(7,8)$. In vivo trials with green tea and resveratrol also decreased serum concentrations $(9,10)$. Clinical studies conducted in the United States, a non-soy-consuming culture, have reported increased IGF-1 with soy supplementation $(11,12)$.

Seaweed has not been studied for its effects on IGF-1, although it shows antitumor activity in both in vitro and in vivo breast cancer studies (13-16). In further support for a role in breast cancer prevention, a case-control study of women in Korea reported that women with the highest seaweed intake had about half the rate of breast cancer as women who infrequently or never consumed seaweed (17). The best-studied mechanism for its antitumor activity is the high antioxidant effects observed in both laboratory and clinical settings (1820). The antioxidants characteristic of seaweed include bioactive compounds not found in land plants, including fucoidan, fucoxanthin, and phlorotannins (21).

In this clinical trial conducted with American women, we investigated the importance of dietary seaweed and soy and their impact on several known biomarkers of breast cancer risk, including serum concentrations of IGF-1 and its main binding protein, IGFBP-3.

\section{EXPERIMENTAL METHODS}

\section{Study Population}

Data for this analysis were collected as part of a trial investigating the effects of seaweed and soy on a number of breast-cancer-related endpoints, including estrogens, phytoestrogens, and thyroid function $(22,23)$. All participants were healthy postmenopausal European-American women living in central Massachusetts. This study was conducted 
according to the guidelines described in the Declaration of Helsinki, and all procedures involving human subjects/patients were approved by the University of Massachusetts Medical School Institutional Review Board. Written informed consent was obtained from all subjects/patients.

Inclusion criteria were: postmenopausal (self-reported cessation of menstruation for more than $1 \mathrm{yr}$ ); not allergic to seaweed, soy, shellfish, or iodine; non-smoking; euthyroid (no diagnosis or treatment for thyroid dysfunction within the previous $5 \mathrm{yr}$ ); negative for thyroid peroxidase (TPO) antibodies as determined by screening; no hormone replacement therapy or, for breast cancer survivors, no chemotherapy or radiation treatments within the preceding $6 \mathrm{mo}$; no history of cancer (other than breast cancer); no current gastrointestinal disorders or diagnosis of diabetes; omnivorous eating habits including meat and dairy products more than twice per wk; and no medications containing antibiotics or corticosteroids within the previous 3 mo. Women continued to eat their normal diets, avoiding seaweed and phytoestrogen-rich foods, and continued habitual intake of vitamins, supplements, and medications during the study.

Women were recruited by word of mouth, physician referrals, and through responses to a newspaper article. Thirty-three women were enrolled into the study and provided baseline data. Decreased IGF-1 has been noted in women taking Tamoxifen, so the 3 women who were taking antiestrogens ( $2 \mathrm{BCS}$ and $1 \mathrm{NBC}$ for osteoporosis) were excluded from the analyses. This left a final study sample of 30 women (mean age $58.4 \mathrm{yr}, 95 \%$ CI 55.5-61.4), among whom 11 were breast cancer survivors (Stage 1 or 2 at diagnosis but with no evidence of disease at the time of the study) and 19 had never been diagnosed with breast cancer.

\section{Experimental Design and Dietary Treatments}

To minimize possible seasonal effects, all women began the study the same week in late October. The study used an unbiased, randomized, placebo-controlled crossover design. Prior to the first clinic visit, all eligible participants were assigned to a treatment group using a computer-generated random number table. Treatment arms were either 1) $7 \mathrm{wk}$ of $5 \mathrm{~g} / \mathrm{day}$ seaweed powder (10 capsules) or $207 \mathrm{wk}$ of $5 \mathrm{~g} /$ day maltodextrin in 10 identical gelatin capsules followed by a 3-wk washout period and then crossed over to the alternate treatment arm (Fig. 1). During Week 7, women consumed a daily soy protein isolate supplement in addition to the $5 \mathrm{~g}$ /day seaweed or placebo. All capsules were taken with the last meal of the day.

Fasting blood samples were collected at the end of each treatment period. To assure blinded laboratory analysis, each patient at each clinic visit was assigned a unique random ID number.

\section{Seaweed and Placebo}

Alaria esculenta (L.) Greville grows along the northeastern shores of North America. It was chosen for its low-iodine content $(95 \mu \mathrm{g} / \mathrm{g})(22)$. The Alaria for this study was collected at maximum reproductive maturity in late June from the Sally Islands by Maine Seaweed Company (Stuben, ME), following standard collection protocols (22). A $5 \mathrm{~g}$ serving of dried Alaria harvested in the same area contains $54.6 \mathrm{~kJ}, 0.9 \mathrm{~g}$ protein, $7.5-9.8 \mu \mathrm{g}$ folate, $475 \mu \mathrm{g}$ iodine, $0.18 \mathrm{~g}$ fat, $2 \mathrm{~g}$ carbohydrate, $1.9 \mathrm{~g}$ fiber, $373 \mathrm{mg}$ potassium, and $212 \mathrm{mg}$ sodium (24). Maltrin M100 maltodextrin (Grain Processing Corporation, Muscatine, IA) was used as placebo, and $5 \mathrm{~g} /$ day provided $75.6 \mathrm{~kJ}$ of total energy. 
The seaweed was milled and both the seaweed and placebo powders were encapsulated into identical gelatin capsules (Beehive Botanicals, Hayward, WI). No fillers or binders were added to the seaweed or placebo powder.

\section{Soy Protein Isolate}

A soy protein ingredient made with soy protein isolate [High Protein Nutritious Food Ingredient Powder (AB1.2 HG 20CA 29 Lot \#G198-8)] was provided by Solae, LLC. (St. Louis, MO). It contained $1.43 \mathrm{mg} / \mathrm{g}$ total isoflavones (expressed as aglycone equivalents). A dose of $2 \mathrm{mg}$ isoflavones $/ \mathrm{kg}$ body weight was calculated for each woman. The mean dose was $100 \mathrm{~g} /$ day soy powder, providing $67 \mathrm{~g}$ of soy protein containing $85 \mathrm{mg}$ genistein, $50 \mathrm{mg}$ daidzein, and $8 \mathrm{mg}$ glycitein.

\section{Blood Collection and Handling}

Blood samples were drawn from fasting participants between $6: 30$ and 10:30 by venipuncture at a consistent time for each subject at baseline and at the end of each treatment period. Serum was harvested within $1 \mathrm{~h}$ by low-speed centrifugation at $4^{\circ} \mathrm{C}$ and stored at $-80^{\circ} \mathrm{C}$.

\section{IGF-1 and IGFBP-3 Analyses}

Active IGF-1 and IGFBP-3 were measured with 2-site immunoradiometric assay (IRMA) (DSL-5600, Diagnostic Systems Laboratories, Inc., Webster, TX) in serum sample aliquots that had not been previously thawed following the manufacturer's protocols. Laboratory personnel were unaware of the treatment status or breast cancer history of the study subjects.

\section{Statistical Analyses}

Statistical analyses followed the same procedures as in our two earlier studies $(22,23)$. Simple descriptive statistics were used to characterize the study sample. Two women withdrew because of mild side effects that resolved when seaweed intake ceased: 1 had reactivated esophageal reflux and 1, with a history of allergic reactions to medications, developed a skin rash and itchy eyes. A third woman withdrew halfway through the study on the advice of her naturopath. All 3 women had participated in the first 3 data collection points and therefore had contributed meaningful data to analyses. Because our statistical models use all available data without imputation, the standard Intention to Treat approach (25) was justified and included all available data from these women.

To test the primary study hypotheses, a repeated-measures analysis of variance (ANOVA) was conducted using Proc Mixed in SAS. In these models, subject was fit as the repeated factor, while treatment group [4 levels: placebo, seaweed, soy, and SeaSoy (combination of seaweed and soy)], sequence of treatment administration, disease status, and age were fit as independent variables.

Individual models were run for IGF-1, IGFBP-3, and the IGF-1:IGFBP-3 ratio. Results are presented as least-squares means (LSMeans; these are the covariate-adjusted means obtained from the mixed model) with 95\% confidence intervals (95\% CI). Linear contrasts were created in Proc Mixed to test for the main effects of seaweed, soy, and SeaSoy relative to placebo. For the 3 main effects, the difference was calculated separately between the LSMeans for each treatment and the placebo. To test for the interaction effect of SeaSoy, the difference was calculated as the LSMean for SeaSoy-the sum of the LSMeans for seaweed and soy. Statistical significance was determined using a $t$-test of the Ho: the difference $=0$ and was evaluated at $P=0.05$. 


\section{RESULTS}

There were no significant differences in age, BMI [body mass index $=$ weight $(\mathrm{kg}) /$ height $\left.(\mathrm{m})^{2}\right]$, weight, physical exercise, parity, breast cancer treatments, and baseline IGF-1 and IGFBP-3 between breast cancer survivors and the volunteers without a history of breast cancer (Table 1).

Although all values were within the normal range of IGF-1 (14.9-64.5 nmol/L), the mean serum concentration of the IGF-1 differed significantly by dietary intervention (Table 2). When taking the placebo, women had a mean IGF-1 serum concentration of $16.9 \mathrm{nmol} / \mathrm{L}$, which significantly increased by about $25 \%$ after the soy supplement period $(21.1 \mathrm{nmol} / \mathrm{L} ; P$ $<0.0001)$. The interaction term tested for synergy; that is, whether the influence of seaweed plus soy was different than simply additive. This was significant for IGF-1 when soy and seaweed were given together, halving the soy-driven increase in IGF-1 (19.4 for SeaSoy, $21.2 \mathrm{nmol} / \mathrm{L}$ for soy alone; $P<0.01)$. Serum concentrations of the IGFBP-3 did not vary significantly with dietary treatment. The IGF-1 to IGFBP-3 ratio increased significantly with seaweed $(0.86$ compared to $0.108 ; P<0.02)$.

\section{DISCUSSION}

Evidence for an effect of soy on IGF-1 is inconsistent. Clinical studies of soy supplements in American women have reported significantly increased IGF-1 serum concentrations. This is counterintuitive, as soy is commonly eaten in Asia, where breast cancer rates are very low.

Three epidemiological studies of postmenopausal women in countries where seaweed is not a common daily food (Nether-lands, Singapore, and China) have reported no association between IGF-1 and soy intake (26-28).

Observational data from Japan indicate that tofu consumption is associated with decreased IGF-1 serum concentration (29). To investigate the relative impact of a Japanese and an Americanized diet on IGF-1, Takata and colleagues compared tofu consumption and IGF-1 concentrations of Japanese women in Japan, Japanese-American women living in Hawaii, and European-American women living in Hawaii (30). Tofu consumption in Japan was associated with an $11 \%$ decrease in IGF-1 serum concentration but made no difference for women in Hawaii. The authors attributed these differences to the wider context of a typical Japanese diet. In further support for the dietary context for soy metabolism, a recent study of post-menopausal women in Singapore reported a dose-response reduction in breast cancer risk with increasing consumption of fruits, vegetables, and soy (31).

The reasons for these discrepancies may be related to the use of soy powder rather than soy foods such as tofu, or it may be related to the presence or absence of other common foods in the diet. Seaweed is a common food in Japan and Korea, but less frequently consumed in other Asian countries. Japanese intake of seaweed, as estimated by the Japanese Ministry of Health, is $12 \mathrm{~g} / \mathrm{d}$ (32). Green tea, another common food in Japan and Korea, has also been shown to significantly lower soy-induced increased IGF-1 in vivo (33).

The limitations of our study include using only one kind of seaweed, rather than a combination of several seaweeds as they are commonly consumed in Japan; using soy powder rather than soy foods; and focusing exclusively on European-American women. On the other hand, though these limitations may limit the applicability to Asian-Western differences in breast cancer risk, they may shed light on how soy powder and seaweeds are metabolized in a non-Western population. As the addition of soy protein powder to the American diet is more likely than daily inclusion of tofu, our results indicating the 
importance of co-factor foods such as seaweed may be relevant in reducing breast cancer risk that might be associated with supplemental soy protein powders.

\section{Acknowledgments}

This study was funded by grants to JT from the Susan G Komen Foundation (Grant 9735) and the U.S. Army Medical Research and Materiel Command under DAMD 17-98-1-8207. The soy protein isolate was donated by Solae, LLC (formerly Protein Technologies, Inc., St. Louis, MO). Dr. Hébert was supported by an Established Investigator Award in Cancer Prevention and Control from the Cancer Training Branch of the National Cancer Institute (K05 CA136975).

\section{References}

1. Matsuno R, Anderson W, Yamamoto S, Tsukuma H, Pfeiffer R, et al. Early-and late-onset breast cancer types among women in the United States and Japan. Cancer Epidemiol Biomarkers Prev. 2007; 16:1437-1442. [PubMed: 17627009]

2. Shimizu H, Ross R, Bernstein L, Yatani R, Henderson B, et al. Cancers of the prostate and breast among Japanese and white immigrants in Los Angeles County. Br J Cancer. 1991; 63:963-966. [PubMed: 2069852]

3. Deapen D, Liu L, Perkins C, Bernstein L, Ross R. Rapidly rising breast cancer incidence rates among Asian-American women. Int J Cancer. 2002; 99:747-750. [PubMed: 12115511]

4. Key T, Appleby P, Reeves G, Roddam A. Endogenous Hormones and Breast Cancer Collaborative Group T. Insulin-like growth factor 1 (IGF1), IGF binding protein 3 (IGFBP3), and breast cancer risk: pooled individual data analysis of 17 prospective studies. Lancet Oncol. 2010; 11:530-542. [PubMed: 20472501]

5. Belfiore A, Frasca F. IGF and insulin receptor signaling in breast cancer. J Mammary Gland Biol Neoplasia. 2008; 13:381-406. [PubMed: 19016312]

6. Velcheti V, Govindan R. Insulin-like growth factor and lung cancer. J Thorac Oncol. 2006; 1:607610. [PubMed: 17409926]

7. Qin L, He K, Xu J. Milk consumption and circulating insulin-like growth factor-I level: a systematic literature review. Int J Food Sci Nutr. 2009; 60 (Suppl):330-340. [PubMed: 19746296]

8. Riso P, Brusamolino A, Martinetti A, Porrini M. Effect of a tomato drink intervention on insulinlike growth factor (IGF)-1 serum levels in healthy subjects. Nutr Cancer. 2006; 55:157-162.

[PubMed: 17044770]

9. Zhou J-R, Li L, Pan W. Dietary soy and tea combinations for prevention of breast and prostate cancers by targeting metabolic syndrome elements in mice. Am J Clin Nutr. 2007; 86:S882-S888. [PubMed: 18265483]

10. Baur J, Pearson K, Price N, Jamieson H, Lerin C, et al. Resveratrol improves health and survival of mice on a high-calorie diet. Nature. 2006; 444:337-342. [PubMed: 17086191]

11. Arjmandi B, Khalil D, Smith B, Lucas E, Juma S, et al. Soy protein has a greater effect on bone in postmenopausal women not on hormone replacement therapy, as evidenced by reducing bone resorption and urinary calcium excretion. J Clin Endocrinol Metab. 2003; 88:1048-1054. [PubMed: 12629084]

12. Wangen K, Duncan A, Merz-Demlow B, Xu X, Marcus R, et al. Effects of soy isoflavones on markers of bone turnover in premenopausal and postmenopausal women. J Clin Endocrinol Metab. 2000; 85:3043-3048. [PubMed: 10999783]

13. Teas J, Harbison M, Gelman R. Dietary seaweed (Laminaria) and mammary carcinogenesis in rats. Cancer Res. 1984; 44:2758-2761. [PubMed: 6426785]

14. Funahashi H, Imai T, Mase T, Sekiya M, Yokoi K, et al. Seaweed prevents breast cancer? Jpn J Cancer Res. 2001; 92:483-487. [PubMed: 11376555]

15. Liu J, Bignon J, Haroun-Bouhedja F, Bittoun P, Vassy J, et al. Inhibitory effect of fucoidan on the adhesion of adenocarcinoma cells to fibronectin. Anticancer Res. 2005; 25:2129-2133. [PubMed: 16158954] 
16. Yamasaki-Miyamoto Y, Yamasaki M, Tachibana H, Yamada K. Fucoidan induces apoptosis through activation of caspase-8 on human breast cancer MCF-7 cells. J Agric Food Chem. 2009; 57:8677-8682. [PubMed: 19754176]

17. Yang Y, Nam S, Kong G, Kim M. A case-control study on seaweed consumption and the risk of breast cancer. Br J Nutr. 2010; 103:1345-1353. [PubMed: 19968892]

18. Cumashi A, Ushakova N, Preobrazhenskaya E, D'Incecco A, Piccoli A, et al. A comparative study of the anti-inflammatory, anticoagulant, antiangiogenic, and antiadhesive activities of nine different fucoidans from brown seaweeds. Glycobiology. 2007; 17:541-552. [PubMed: 17296677]

19. Kang K, Park Y, Hwang HJ, Kim SH, Lee JG, et al. Antioxidative properties of brown algae polyphenolics and their perspectives as chemopreventive agents against vascular risk factors. Arch Pharm Res. 2003; 26:286-293. [PubMed: 12735686]

20. Khan M, Choi J, Lee M, Kim E, Nam T, et al. Antiinflammatory activities of methanol extracts from various seaweed species. J Environ Biol. 2008; 29:465-469. [PubMed: 19195382]

21. O'Sullivan L, Murphy B, McLoughlin P, Duggan P, Lawlor P, et al. Prebiotics from marine macroalgae for human and animal health applications. Mar Drugs. 2010; 8:2038-2064. [PubMed: 20714423]

22. Teas J, Braverman L, Kurzer M, Pino S, Hurley T, et al. Seaweed and soy: companion foods in Asian cuisine and their effects on thyroid function in American women. J Med Food. 2007; 10:90100. [PubMed: 17472472]

23. Teas J, Hurley T, Hebert J, Franke A, Sepkovic D, et al. Dietary seaweed modifies estrogen and phytoestrogen metabolism in healthy post-menopausal women. J Nutr. 2009; 139:939-944. [PubMed: 19321575]

24. Maine Coast Sea Vegetables. Nutritional Analysis of Maine Coast Sea Vegetables. Franklin, ME: Maine Coast Sea Vegetables; 1985.

25. Rothman, KJ.; Greenland, S., editors. Modern Epidemiology. 2. Lippincott-Raven; Philadelphia: 1998.

26. Vrieling A, Voskuil D, Bueno de Mesquita H, Kaaks R, van Noord P, et al. Dietary determinants of circulating insulin-like growth factor (IGF)-I and IGF binding proteins 1, -2 and -3 in women in the Netherlands. Cancer Causes Control. 2004; 15:787-796. [PubMed: 15456992]

27. Probst-Hensch N, Wang H, Goh V, Seow A, Lee H, et al. Determinants of circulating insulin-like growth factor I and insulin-like growth factor binding protein 3 concentrations in a cohort of Singapore men and women. Cancer Epidemiol Biomark Prev. 2003; 12:739-746.

28. Sanderson M, Shu X, Yu H, Dai Q, Malin A, et al. Insulin-like growth factor-I, soy protein intake, and breast cancer risk. Nutr Cancer. 2004; 50:8-15. [PubMed: 15572292]

29. Maruyama K, Iso H, Ito $\mathrm{Y}$, Watanabe $\mathrm{Y}$, Inaba $\mathrm{Y}$, et al. Associations of food and nutrient intakes with serum IGF-I, IGF-II, IGFBP-3, TGF- $\beta 1$, total SOD activity and sFas levels among middleaged Japanese: the JACC Study. Asian Pacific J Cancer Prev. 2009; 10(Suppl):7-22.

30. Takata Y, Maskarinec G, Franke AA, Nagata C, Shimizu H. A comparison of dietary habits among women in Japan and Hawaii. Public Health Nutr. 2004; 7:319-326. [PubMed: 15003140]

31. Butler L, Wu A, Wang R, Koh W, Yuan J, et al. A vegetable-fruit-soy dietary pattern protects against breast cancer among postmenopausal Singapore Chinese women. Am J Clin Nutr. 2010; 91:13-19.

32. Ministry of Health of Japan. The National Nutrition Survey in Japan, 2002 [in Japanese]. Daiichi shuppan; Tokyo, Japan: 2004.

33. Zhou J-R, Yu L, Mai Z, Blackburn G. Combined inhibition of estrogen-dependent human breast carcinoma by soy and tea bioactive components in mice. Int J Cancer. 2004; 108:8-14. [PubMed: 14618609] 


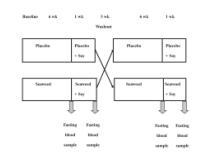

FIG. 1.

Study design showing timing of the 4 data collection points. 
TABLE 1

Characteristics of the healthy postmenopausal women study participants $(N=30)$

\begin{tabular}{|c|c|c|c|}
\hline Characteristic & Breast Cancer Survivors & No History of Breast Cancer & $P$ Value \\
\hline \multirow[t]{2}{*}{ No. of volunteers } & 11 & 19 & \\
\hline & Mean $(95 \% \mathrm{CI})$ & Mean $(95 \% \mathrm{CI})$ & \\
\hline Age (yr) & $60.1(54.9-65.3)$ & $57.5(53.6-61.4)$ & 0.39 \\
\hline BMI $\left(\mathrm{kg} / \mathrm{m}^{2}\right)$ & $27.1(22.8-31.4)$ & $26.6(24.6-28.6)$ & 0.80 \\
\hline Weight (kg) & $71.8(61.2-82.4)$ & $72.3(67.2-77.4)$ & 0.92 \\
\hline Years postmenopausal (yr) & $12.7(5.2-20.3)$ & $7.5(3.9-11.2)$ & 0.14 \\
\hline IGF-1 at baseline (nmol/L) & $17.0(12.6-21.3)$ & $17.6(14.1-21.2)$ & 0.81 \\
\hline IGFBP-3 at baseline $(\mathrm{nmol} / \mathrm{L})$ & $160.7(127.2-194.2)$ & $188.8(164.1-213.6)$ & 0.16 \\
\hline Years post-BC diagnosis (yr) & $5.3(2.3-8.3)$ & $\mathrm{N} / \mathrm{A}^{a}$ & \\
\hline Physical exercise (h/wk) & $n(\%)$ & $n(\%)$ & \\
\hline None & $4(36)$ & $6(32)$ & \\
\hline Low $(\leq 60 \mathrm{~min})$ & $2(18)$ & $5(26)$ & \\
\hline $\operatorname{High}(>60 \mathrm{~min})$ & $5(45 \%)$ & $8(42)$ & \\
\hline \multicolumn{4}{|l|}{ Parity } \\
\hline Nulliparous & $2(18)$ & $3(16)$ & \\
\hline 1 & $1(9)$ & $2(11)$ & \\
\hline 2 & $4(36)$ & $4(21)$ & \\
\hline 3 & $1(9)$ & $6(32)$ & \\
\hline$>3$ & $3(27)$ & $4(21)$ & \\
\hline \multicolumn{4}{|l|}{ Breast cancer treatment } \\
\hline Surgery & $11(100)$ & N/A ${ }^{a}$ & \\
\hline Chemotherapy & $3(27)$ & $\mathrm{N} / \mathrm{A}^{a}$ & \\
\hline Radiation & $5(45)$ & $\mathrm{N} / \mathrm{A}^{a}$ & \\
\hline
\end{tabular}

${ }^{a}$ N/A: not applicable. 
TABLE 2

Comparison of IGF-1 and IGFBP-3 serum concentrations in healthy postmenopausal women on placebo, seaweed, soy, and seasoy treatments $(N=30)$

\begin{tabular}{lcccc}
\hline Serum Concentration $^{a}$ & Placebo Mean (95\% CI) & Seaweed Mean (95\% CI) & Soy Mean (95\% CI) & Seasoy Mean (95\% CI) \\
\hline IGF-1 (nmol/L) & $16.9(14.6-19.2)$ & $18.1(15.8-20.5)$ & $21.2(18.9-23.5)$ & $19.4(17.0-21.7)$ \\
$P$ values ${ }^{b}$ & & 0.15 & 0.0001 & $0.004,0.01$ \\
IGFBP-3 (nmol/L) & $191.9(172.0-211.7)$ & $174.4(153.6-195.3)$ & $209.5(189.0-230.0)$ & $198.4(177.6-219.2)$ \\
$P$ values &
\end{tabular}

